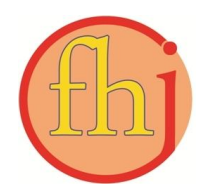

Faletehan Health Journal, 5 (2) (2018) 90-98

https://journal.Ippm-stikesfa.ac.id

ISSN 2088-673X | e-ISSN 2597-8667

\title{
Studi Kasus: Asuhan Keperawatan Pada Klien Isolasi Sosial Pasca Pasung
}

\author{
Muhammad Fadly ${ }^{1}$, Giur Hargiana ${ }^{1 *}$ \\ ${ }^{1}$ Fakultas IImu Keperawatan Universitas Indonesia, Kampus FIK UI \\ *Corresponding Author: giurhargiana@ui. ac. id
}

\begin{abstract}
Abstrak
Isolasi sosial merupakan keadaan dimana seorang individu mengalami penurunan bahkan sama sekali tidak mampu berinteraksi dengan orang lain di sekitarnya. Tujuanstudi kasus ini adalah untuk menganalisis tentang asuhan keperawatan isolasi sosial pasca pasung pada Tn. P dengan skizofrenia paranoid. Proses asuhan keperawatan dilakukan berdasarkan standar asuhan keperawatan generalis selama enam hari rawat pada tanggal 7-12 M ei 2018 pada Tn. P dengan usia 32 tahun dan berjenis kelamin laki-laki. Hasil didapatkan masalah keperawatan utama adalah isolasi sosial. Implementasi keperawatan berfokus pada kemampuan klien membina hubungan saling percaya dan meningkatkan kemampuan klien berinteraksi secara bertahap. Intervensi keperawatan memberikan dampak yang positif kepada klien dilihat dengan penurunan tanda dan gejala isolasi sosial pada aspek kognitif, afektif, fisiologis dan sosial, namun belum tampak penurunan pada aspek perilaku. Faktor yang menyebabkan klien sulit membina hubungan dengan perawat yaitu faktor internal dimana klien memiliki penilaian negatif terhadap diri sendiri, orang lain dan lingkungan dan faktor eksternal dimana klien menganggap perawat sebagai stressor yang membahayakan. Rencana tindak lanjut pelayanan keperawatan diharapkan dapat dimaksimalkan baik secara individu, keluarga, kelompok dan komunitas.
\end{abstract}

Kata Kunci: isolasi sosial, skizofrenia paranoid, standar asuhan keperawatan

\begin{abstract}
Social isolation is characterized by decline or loss inability to interact with others. This paper aimed to analyze the nursing care of social isolation on Mr. P with schizophrenia paranoid. The nursing care process is based on the standard of generalist nursing care which provided for six days from May $7^{\text {th }}$ throughout $12^{\text {th }} 2018$ on Mr. P aged 32 years male. $M$ ain nursing problem was social isolation. Nursing intervention was emphasized on client's ability to establish mutual relationship and improve client's communication skills gradually. Nursing interventions affected client positively as manifested gy decreased signs and symptoms of social isolation on the cognitive, affective, physiological and social aspects, but there had not been a decline in behavioral aspects. Client's barriers in establishing relationship with nurses were internal factors in which clients had negative judgments about themselves, others and the environment and external factors where clients considered the nurse as a threatening stressor. Nursing care follow-up plans are expected to be maximized for individually, family, group and community.

Keywords: schizophrenia paranoid, social isolation, standard of nursing care
\end{abstract}


Faletehan Health Journal, 5 (2) (2018) 90-98

https://journal.Ippm-stikesfa.ac.id

ISSN 2088-673X | 2597-8667

\section{Pendahuluan}

Gangguan jiwa (psikosis) merupakan suatu keadaan jiwa yang tidak mempunyai hubungan dengan realitas, dimana selama periode gangguan jiwa, individu tersebut tidak menyadari apa yang dialami orang lain tentang hal yang sama dan orang lain tidak mempunyai respons dengan cara yang sama ( Stuart, Keliat \& Pasaribu, 2016). Gangguan jiwa yang banyak dirawat di rumah sakit adalah skizofrenia dengan angka prevalensi skizofrenia di dunia cukup tinggi yaitu sekitar 24 juta orang, sedangkan di Indonesia berdasarkan laporan Riset Kesehatan Dasar 2013 berjumlah 1,7 permil atau dapat dikatakan bahwa terdapat satu sampai dua orang yang mengalami gangguan jiwa dalam seribu penduduk Indonesia (Kemenkes, 2013; WHO, 2011).

Isolasi sosial adalah salah satu diagnosis keperawatan berdasarkan tanda negatif dari klien skzofrenia. Isolasi sosial terjadi dipengaruhi oleh berbagai faktor yaitu usia, gender, pendidikan, pekerjaan, latar belakang budaya, keyakinan religi, politik, kemiskinan, penghasilan rendah, tinggal sendirian, penyakit kronis, tidak mempunyai anak, tidak ada kontak dengan keluarga dan kesulitan akses transportasi (Massom, 2016; DeVylder \& Hilimire, 2015; Junardi, Daulima \& Wardani, 2015; Wakhid, Hamid \& Helena, 2013). Perbedaan jenis kelamin juga dapat menjadi faktor terjadinya isolasi sosial yaitu jenis kelamin laki-laki lebih banyak dibandingkan wanita (Penaloza, Fuentealba \& Gallardo, 2017). Berbagai faktorfaktor di atas sangat penting untuk diperbaiki agar tidak menimbulkan dampak isolasi sosial yang semakin luas.

Isolasi sosial telah dikenal mempunyai dampak yaitu sebagai faktor risiko terjadinya morbiditas dan mortalitas (Cacioppo et al, 2015). Individu yang mengalami isolasi sosial yang berkepanjangan dapat menyebabkan munculnya masalah lain yaitu menarik diri, halusinasi, defisit perawatan diri dan risiko perilaku kekerasan (Trimelia, 2011). Perawat sangat dibutuhkan untuk berperan dalam mengurangi dan mencegah akibat yang lebih lanjut yang dapat memperburuk klien.

Tindakan keperawatan klien isolasi sosial yaitu dengan cara membantu klien mengidentifikasi penyebab, manfaat mempunyai teman,kerugian tidak mempunyai teman, latihan berkenalan dengan orang lain secara bertahap (Keliat \& Akemat, 2010). Beberapa studi telah dilakukan untuk mengatasi masalah isolasi sosial dengan memberikan berbagai intervensi keperawatan yaitu Social Affiliation Enhancement Tasks,SocializationEnhancement, Social Network Intervention, Behavior Modification: socialskills, e-Intervention, Terapi Aktivitas Kelompok Sosialisai (TAKS), Strategies Against Stigma and Discrimination (SASD), Psychoeducation Social Skills Training (SST), dan Cognitive Behavioral Therapy (CBT) (Kopelowicz \& Liberman, 2003; Li, et al, 2010; Gomes \& Miguel, 2012; Tarzian, et al, 2013; Bulechek,Bulechek, et al, 2013; McCarthy, et al, 2017; Chipps, Jarvis \& Ramlall, 2017).

Penulis menemukan dari 20 klien yang ada di ruang Subadra RSMM Bogor dan dirawat oleh mahasiswa praktik profesi Ners didapatkan sebanyak 12 orang atau $60 \%$ mengalami isolasi sosial. Penulis melakukan pengelolaan asuhan keperawatan pada klien Tn. $\mathrm{P}$ dengan diagnosis keperawatan isolasi sosial selama enam hari perawatan. Tanda dan gejala yang didapatkan pada Tn. P yaitu klien menghindari pembicaraan dengan cara pergi secara tiba-tiba saat diajak interaksi, pembicaraan seadanya, pelan dan sulit didengar, senang menyendiri di kamar dan tampak takut bertemu dengan orang lain. Klien mengatakan tidak mau berhubungan dengan orang lain karena merasa takut ketika berhadapan dengan orang lain.

Upaya untuk mengatasi masalah isolasi sosial pada Tn. P adalah dengan meningkatkan hubungan saling percaya kepada klien secara bertahap, memenuhi kebutuhan aktivitas harian klien, dan meningkatkan kemampuan yang dimiliki klien yaitu selalu mengajak klien interaksi, berbincangbincang dan mulai melakukan berkenalan secara bertahap dengan beberapa orang klien dan perawat yang ada di Ruang Subadra. Berdasarkan latar belakang yang telah diuraikan di atas mendasari penulis untuk melakukan analisis lebih lanjut mengenai asuhan keperawatan pada klien dengan masalah keperawatan isolasi sosial di ruang Subadra Rumah Sakit dr. Marzoeki Mahdi Bogor.

\section{Gambaran Kasus}

Klien Tn. P, usia 32 tahun, jenis kelamin lakilaki, belum menikah, pekerjaan swasta, masuk ke RSMM tanggal 16 April 2018 dengan diagnosis medis skizofrenia paranoid. Klien dibawa ke rumah sakit karena mengamuk di rumah, meresahkan keluarga dan masyarakat, berperilaku 
aneh, sering marah-marah dan bicara sendiri. Klien mengalami gejala berperilaku aneh sejak 13 tahun yang lalu mulai berobat secara tradisional namun penyakit bertambah parah dan akhirnya dibawa ke rumah sakit. Sebelum masuk rumah sakit klien sempat dipasung dengan cara dikurung di kamar dan tangan diikat.

Saat dilakukan pengkajian tanggal 7 Mei 2018 klien tampak mondar-mandir tanpa tujuan yang jelas, pakaian tidak rapi, celana miring, rambut panjang dan tidak rapi, gigi kotor, kuku panjang dan kotor, kontak mata kurang, sering menatap ke satu arah dalam waktu yang lama, mulut berkomat kamit dengan suara yang pelan, tubuh tampak membungkuk, gerakan kaki berulang-ulang seperti orang yang sedang berjalan di tempat. Pembicaraan baik namun suara pelan dan klien tidak mampu berinteraksi dalam waktu yang lama, tidak mampu berkonsentrasi, kehilangan rasa tertarik pada kegiatan sosial, klien tidak mampu memulai pembicaraan, menjawab pertanyaan seadanya, klien merasa tidak aman di dekat orang lain, dan cenderung menghindari pembicaraan dengan cara pergi meninggalkan perawat tanpa sebab. Ketika ditanya bagaimana perasaannya klien menjawab tidak nyaman dan takut bertemu orang lain. Klien mengatakan belum mandi, sikat gigi dan potong kuku. Ketika ditanya apakah mendengan atau melihat sesuatu yang tidak nyata klien mengatakan tidak ada, namun baru pada hari ke 5 klien mengatakan mendengar suara harimau.

Klien belum pernah masuk rumah sakit gangguan jiwa pada masa lalu dan belum pernah mendapat pengobatan sebelumnya, namun klien pernah dibawa ke puskesmas dan mendapat pengobatan di puskesmas namun kurang berhasil. Klien mempunyai riwayat melakukan kekerasan fisik yaitu dengan merusak kaca rumah dan mengamuk tanpa sebab yang jelas. Sebelum sakit klien bekerja sebagai supir angkutan kota dan dikenal dengan orang yang rajin bekerja, namun klien menjadi berubah dan menjadi berperilaku aneh tanpa sebab atau mempunyai suatu masalah yang jelas. Riwayat anggota keluarga yang mengalami gangguan jiwa tidak ada, namun klien ketika ditanya pengalaman tidak menyenangkan klien mengatakan pernah dikurung di kamar.

Klien mengatakan dirinya biasa saja, ketika ditanya bagian tubuh yang tidak disukai klien menunjukkan kaki kanannya dan ketika ditanya bagian tubuh yang disukai klien tidak menunjuk bagian tubuh manapun. Klien mengatakan sebelum dirawat klien bekerja sebagai supir angkutan kota. Klien mengatakan sekolah hanya sampai SMP. Ketika ditanya apakah klien merasa puas dirinya sebagai laki-laki klien menjawab puas. Klien berperan sebagai anak ketika di ruamah dan sebagai supir di kelompok angkutan kota. Klien mampu melaksanakan peran sebagai supir dan menyetir mobil dengan baik. Ketika ditanya harapan klien menjawab ingin sembuh dan cepat pulang, ingin segera bekerja kembali, ingin menikah dan berkeluarga. Ketika sakit klien sering mondar mandir di rumah, tidak mempunyai teman dan tidak mau keluar rumah. Keluarga mengatakan klien mempunyai sifat pemalu dan betah tinggal di rumah.

Berdasarkan hasil pengkajian dan analisis data didapatkan diagnosis keperawatan yaitu risiko perilaku kekerasan, isolasi sosial, defisit perawatan diri, gangguan sensori persepsi halusinasi pendengaran, dan harga diri rendah kronis. Diagnosis keperawatan utama yang diangkat berdasarkan prioritas adalah isolasi sosial. Data subjektif didapatkan klien mengatakan takut bertemu orang lain. Data objektif yang ditemukan yaitu klien bicara pelan, kontak mata kurang, mudah beralih, menghindari pembicaraan dan suara pelan, tidak mampu berinteraksi dalam waktu yang lama, klien tidak mampu memulai pembicaraan, klien menjawab pertanyaan seadanya, menghindari pembicaraan dengan pergi meninggalkan perawat.

Rencana tindakan keperawatan pada klien: Tujuan tindakan keperawatan untuk klien yaitu: 1) membina hubungan saling percaya; 2) menyadari penyebab isolasi sosial; dan 3) berinteraksi dengan orang lain. Tindakan keperawatan yang dapat diberikan yaitu: 1) membina hubungan saling percaya; 2) membantu klien mengenal penyebab isolasi sosial; 3) membantu klien mengenali keuntungan dari membina hubungan dengan orang lain; 4) membantu klien mengenal kerugian dari tidak membina hubungan; 5) membantu klien untuk berinteraksi dengan orang lain secara bertahap (Keliat, Akemat, Helena, \& Nurhaeni, 2011).

Implementasi keperawatan pada hari pertama didapatkan data subjektif klien mengatakan ingin pulang dan klien mengatakan tidak mengatakan tidak mengenal siapapun di sini. Data objektif yang ditemukan yaitu mondar- mandir di kamar, kontak mata kurang, gerakan kaki berulang-ulang, klien menghindari pembicaraan. Diagnosis keperawatan 
Faletehan Health Journal, 5 (2) (2018) 90-98

https://journal.Ippm-stikesfa.ac.id

ISSN 2088-673X | 2597-8667

yaitu isolasi sosial. Implementasi keperawatan yang dilakukan yaitu membina hubungan saling percaya, mengidentifikasi penyebab isolasi sosial, memasukkan kegiatan ke dalam jadwal harian. Rencana tindak lanjut latih mengenal isolasi sosial dan cara berkenalan. Evaluasi subjektif yaitu klien mengatakan ingin kembali ke kamar. Evaluasi objektif yang mau berjabat tangan, mau menjawab salam, menyebutkan nama, belum mampu mengingat nama perawat, kontak mata kurang, klien menghindari pembicaraan dengan pergi tanpa sebab, klien belum mampu mengenal isolasi social dan klien belum mampu mempraktekkan cara berkenalan. Analisis masalah isolasi sosial belum teratasi. Planning bagi klien yaitu latih mengenal isolasi sosial.

Implementasi keperawatan pada hari ke-dua didapatkan data subjektif klien mengatakan ingin pulang dan klien mengatakan belum mempunyai teman. Data objektif yaitu mondar-mandir di kamar, kontak mata kurang, gerakan kaki berulang-ulang dan klien menghindari pembicaraan. Diagnosis keperawatan yaitu isolasi sosial. Implementasi keperawatan yang dilakukan yaitu membina hubungan saling percaya, mengevaluasi kegiatan klien, mengidentifikasi penyebab isolasi sosial, keuntungan berteman dan kerugian tidak berteman dan memasukkan kegiatan ke dalam jadwal harian. Rencana tindak lanjut yaitu ulangi latihan mengenal isolasi sosial dan cara berkenalan. Evaluasi subjektif didapatkan klien mengatakan belum mempunyai teman dan belum mau belajar cara berkenalan. Evaluasi objektif yaitu mau berjabat tangan, menjawab salam, menyebutkan nama, belum mampu mengingat nama perawat, kontak mata kurang, klien menghindari pembicaraan dengan pergi tanpa sebab, klien belum mampu mengenal isolasi sosial dan klien belum mampu mempraktekkan cara berkenalan. Analisis yaitu masalah isolasi sosial belum teratasi. Planning untuk pasien yaitu latih mengenal isolasi sosial.

Implementasi keperawatan pada hari ke-tiga didapatkan data subjektif yaitu klien mengatakan ingin masuk ke kamar. Data objektif didapatkan mondar-mandir, kontak mata kurang, gerakan kaki berulang-ulang dan klien menghindari pembicaraan. Diagnosis keperawatan isolasi sosial. Implementasi keperawatan yaitu membina hubungan saling percaya, mengevaluasi kegiatan harian klien, mengidentifikasi isolasi sosial dan memasukkan kegiatan ke dalam jadwal harian.
Rencana tindak lanjut yaitu ulangi latihan mengenal isolasi sosial dan cara berkenalan dan latih klien berkenalan dengan 1-2 orang perawat/klien. Evaluasi subjektif didapatkan klien mengatakan ingin ke kamar. Evaluasi objektif yaitu mau berjabat tangan, menjawab salam, menyebutkan nama, klien mulai mampu mengingat nama perawat, klien pergi meninggalkan perawat padahal kontrak belum selesai, kontak mata kurang, klien menghindari pembicaraan, klien belum mampu mengenal isolasi sosial dan klien belum mampu mempraktekkan cara berkenalan. Analisis yaitu masalah isolasi sosial belum teratasi. Planning pasien yaitu latih mengenal isolasi sosial.

Implementasi keperawatan pada hari keempat didapatkan data subjektif yaitu klien mengatakan ingin masuk ke kamar dan klien mengatakan tidak mau berkenalan dengan temannya. Data objektif yaitu mondar-mandir, kontak mata kurang, gerakan kaki berulang-ulang, klien menghindari pembicaraan dan klien mulai merangkul perawat. Diagnosis keperawatan yaitu isolasi sosial. Implementasi keperawatan yaitu mengevaluasi kegiatan harian klien, mengidentifikasi isolasi social, melatih klien berkenalan dengan 1 orang klien dan memasukkan kegiatan ke dalam jadwal harian. Rencana tindak lanjut yaitu optimalkan latihan mengenal isolasi sosial dan cara berkenalan, latih berkenalan dengan 1-2 orang klien/perawat dan latih mengikuti aktivitas ruangan sambil berinteraksi dengan orang lain.

Evaluasi subjektif didapatkan yaitu klien mengatakan "mau kemana Pak?" dan klien mengatakan senang ikut jalan-jalan tadi pagi. Evaluasi objektif yaitu klien mulai mau menyapa perawat, klien mampu berinteraksi dengan perawat dengan waktu yang singkat (5 menit), kontak mata kurang, klien berusaha menghindari pembicaraan, klien belum mampu mengenal isolasi sosial dan klien mempraktekkan cara berkenalan dengan 1 orang klien dengan bantuan perawat. Analisis yaitu masalah isolasi sosial belum teratasi. Planning yaitu latih mengenal isolasi sosial dan latih berkenalan dengan 1 orang satu kali sehari.

Implementasi keperawatan pada hari ke-lima didapatkan data subjektif klien mengatakan senang sendirian di kamar. Data objektif didapatkan klien mondar-mandir di kamar, kontak mata kurang, gerakan kaki berulang- ulang, klien menghindari pembicaraan dan tidur malam cukup namun tidur siang kurang. Diagnosis keperawatan yaitu isolasi sosial. Implementasi yang dilakukan yaitu 
mengevaluasi kegiatan harian klien, melatih mengikuti kegiatan yang ada di ruangan, melatih berkenalan dengan 1 orang klien dan memasukkan kegiatan ke dalam jadwal harian. Rencana tindak lanjut yaitu latih mengenal isolasi sosial dan cara berkenalan, latih berkenalan dengan 1 orang perawat dan optimalkan mengikuti kegiatan di ruangan. Evaluasi subjektif didapatkan klien mengatakan senang jalan-jalan di luar dan klien mengatakan ingin pulang. Evaluasi objektif yaitu klien tampak ingin keluar terus, kontak mata kurang, klien mampu berinteraksi dengan perawat dalam waktu yang lebih lama (30 menit) dan klien mempraktekkan cara berkenalan dengan 1 orang klien dengan bantuan perawat. Analisis yaitu masalah isolasi sosial belum teratasi. Planning yaitu latih mengenal isolasi sosial, latih berkenalan $1 \mathrm{x}$ sehari dan latih kegiatan jalan santai setiap pagi.

Implementasi keperawatan pada hari keenam didapatkan data subjektif klien mengatakan ingin sendiri di kamar dan klien mengatakan sudah mandi pagi. Data objektif didapatkan yaitu mondar-mandir, kontak mata kurang, gerakan kaki berulang-ulang dan klien mampu berinteraksi dengan perawat dengan waktu yang singkat. Diagnosis keperawatan isolasi sosial. Implementasi yang dilakukan yaitu mengevaluasi kegiatan harian klien, mengidentifikasi isolasi sosial dan berkenalan dengan 1 orang dan memasukkan kegiatan ke dalam jadwal harian. Rencana tindak lanjut yaitu latih mengenal isolasi sosial dan cara berkenalan dan optimalkan mengikuti kegiatan di ruangan. Evaluasi subjektif didapatkan yaitu klien mengatakan ingin jalanjalan keluar dan ingin pulang. Data objektif didapatkan kontak mata kurang, klien mampu berinteraksi dengan perawat dalam waktu yang singkat, klien belum mampu mengenal isolasi social dan klien mempraktekkan cara berkenalan dengan 1 orang klien dengan bantuan perawat. Analisis yaitu masalah isolasi sosial belumm teratasi. Planning yaitu latih mengenal isolasi sosial, latih berkenalan 1 kali sehari dan latih mengikuti kegiatan jalan santai setiap pagi.

\section{Pembahasan}

Berdasarkan hasil pengkajian didapatkan beberapa faktor predisposisi, faktor presipitasi dan respons terhadap stresor. Tanda gejala isolasi sosial dianalisis berdasarkan batasan karakeristik penegakan diagnosis keperawatan dan kondisi klien. Diagnosis keperawatan menentukan intervensi keperawatan yang akandirencanakan. Model stres adaptasi Stuart cukup efektif untuk menggambarkan kondisi klinis klien dan menggambarkan proses terjadinya isolasi sosial pada klien (Junardi, et al, 2015).

Faktor predisposisi yang didapatkan yaitu usia, jenis kelamin, pekerjaan, status pernikahan dan tingkat pendidikan. Usia 32 tahun yang merupakan usia dewasa awal dan berjenis kelamin laki-laki mempunyai tingkat stres yang tinggi dan dapat memicu gangguan jiwa dimana menurut penelitian usia rata-rata klien dengan masalah isolasi sosial yaitu 31 tahun (Halter, 2014; Wakhid, el al, 2015; Junardi, et al 2015; Stuart, et al, 2016). Pekerjaan dengan penghasilan yang rendah membuat klien sulit memenuhi kebutuhannya sehingga kurang mendapatkan penghargaan dari orang lain dan klien merasa adanya ketidaksesuaian antara keinginan dan kenyataan yang ada, merasa gagal dan tidak berguna (Yosep \& Sutini, 2014; Junardi, et al, 2015). Klien yang belum menikah dapat menjadi faktor terjadinya isolasi sosial karena klien gagal menemukan pasangan hidup, tidak mempunyai pertahanan yang kuat dan stresor yang semakin menumpuk mengakibatkan klien malu untuk bersosialisasi (Cacioppo, et al, 2015; Wakhid, et al, 2013; Junardi, et al, 2015; Napolion, et al, 2012). Penelitian juga menunjukkan bahwa klien isolasi sosial sebagian besar memiliki latar belakang pendidikan menengah dimana sangat memengaruhi klien dalam berperilaku, membuat keputusan, cara menilai stresor dan menyelesaikan masalahnya (Napolion, et al, 2012; Wakhid, et al, 2013).

Faktor presipitasi klien isolasi sosial pada Tn. $\mathrm{P}$ yaitu putus obat. Keluarga klien mengatakan klien pernah dibawa ke puskesmas dan mendapat pengobatan namun hasilnya kurang memuaskan dan akhirnya keluarga memutuskan untuk dibawa ke rumah sakit. Selain putus obat, kondisi penyakit klien yang sudah lama yaitu 13 tahun, menunjukkan klien mengalami keterlambatan dalam penanganan sehingga kondisi gangguan jiwa sudah menjadi kronis. Masalah yang dihadapi klien dalam kurun waktu yang cukup lama membuat stresor yang dihadapi klien menjadi menumpuk. Jumlah stresor yang banyak, baik dari stresor internal maupun stresor eksternal, akan membutuhkan penyelesaian dalam bentuk koping yang semakin banyak pula. Koping yang dibutuhkan mesti adekuat dan bervariasi agar 
Faletehan Health Journal, 5 (2) (2018) 90-98

https://journal.Ippm-stikesfa.ac.id ISSN 2088-673X | 2597-8667

mampu mengatasi stresornya (Stuart, Keliat \& Pasaribu, 2016).

Kondisi klien saat dilakukan pengkajian yaitu didapatkan tanda gejala aspek kognitif merasa tidak aman di dekat orang lain, tidak mampu berkonsentrasi dan kehilangan rasa tertarik pada kegiatan sosial, aspek afektif yaitu merasa tidak nyaman dengan orang lain, afek tumpul dan takut berada dekat orang lain, aspek fisiologis yaitu sulit tidur dan wajah murung, aspek perilaku yaitu tidak ada kontak mata, berdiam diri di kamar, banyak melamun, aspek sosial yaitu menarik diri, sulit berinteraksi dengan orang lain dan curiga terhadap orang lain. Data tersebut masuk dalam batasan karakteristik diagnosis keperawatan isolasi sosial dari NANDA yaitu klien ingin sendiri, menarik diri, merasa tidak aman di tempat umum, tidak ada kontak mata dan adanya tindakan berulang (Herdman \& Kamitsuru, 2015). Townsend (2011) juga menjelaskan batasan karakteristik isolasi sosial yaitu menyendiri di kamar, tidak komunikatif, menarik diri, tidak ada kontak mata, sedih, tidur dengan posisi fetal, mengungkapkan rasa penolakan atau kesepian, aktivitas yang tidak bermakna, dan menolak interaksi.

Penelitian menunjukkan bahwa klien dengan isolasi sosial sulit untuk mencapai hubungan saling percaya karena beberapa faktor yaitu faktor internal dan faktor eksternal. Faktor internal yaitu bahwa klien dengan isolasi sosial memiliki penilaian negatif terhadap diri sendiri, orang lain dan lingkungan sehingga menimbulkan perilaku negatif yaitu menarik diri. Faktor eksternal yang dapat dirasakan oleh klien yaitu pemberi asuhan keperawatan itu sendiri. Penelitian menunjukkan bahwa klien isolasi sosial biasanya menilai bahwa proses pemberian asuhan keperawatan dianggap sebagai suatu stressor yang dapat menimbulkan bahaya bagi klien, yang menyebabkan klien menolak interaksi kepada perawat (Syafrini, et al, 2015; Stuar, et al, 2016).

Hubungan saling percaya dilakukan oleh penulis agar klien lebih nyaman dan percaya dalam menerima perawat yang dibuktikan dengan klien , mau berjabat tangan, mau menjawab salam, mau menyebutkan nama dan mau berkenalan (Syafrini, et al, 2015; Jumaini, Keliat \& Hastono, 2010). Namun klien belum mampu menerima kehadiran perawat yaitu pada saat interaksi klien menghindari pembicaraan dengan cara memutus interaksi dan pergi meninggalkan perawat tanpa alasan yang jelas. Penelitian menunjukkan bahwa terdapat hubungan yang signifikan antara kemampuan perawat pelaksana yang memiliki kemampuan membina hubungan saling percaya dengan tanda dan gejala isolasi sosial dimana perawat yang memiliki kemampuan yang tinggi dapat membantu menurunkan tanda dan gejala klien isolasi sosial (Syafrini, Keliat \& Putri, 2015). Pemberi asuhan hendaknya meningkatkan hubungan perawat dan klien dengan cara hubungan yang alami sehingga klien lebih nyaman dan percaya dalam menerima perawat (Harwood, et al, 2007).

Teknik komunikasi yang dilakukan dalam intervensi klien isolasi sosial yang digunakan yaitu menghadirkan diri (presence) yaitu perawat berada bersama klien baik secara fisik maupun psikologis pada saat klien membutuhkan kehadiran orang lain (Bulechek, et al, 2013). Perawat melakukan menghadirkan diri agar terjadi fondasi yang baik untuk menunjukkan adanya caring dari perawat. Penelitian menunjukkan bahwa kehadiran perawat dapat meningkatkan keefektifan manajemen keperawatan dan meningkatkan caring oleh perawat (Gomes \& Miguel, 2012). Saat melakukan teknik kehadiran ini, respons yang diberikan Tn P yaitu menghindar dan meninggalkan perawat tanpa sebab sehingga kontak sosial menjadi kurang. Penulis melakukan strategi dengan melakukan kontak sosial yang singkat namun sering dalam proses membina hubungan saling percaya. Penelitian menunjukkan adanya hubungan yang signifikan antara frekuensi kontak sosial terhadap gejala negatif, fungsi psikososial dan kalitas hidup klien dengan skizofrenia dimana semakin tinggi kontak sosial klien akan menurunkan gejala negatif skizofrenia dan meningkatkan fungsi sosial secara bersamaan (Siegrist,et al, 2015).

Klien Tn. $P$ juga memiliki diagnosis keperawatan defisit perawatan diri. Hal ini membuat strategi penulis untuk membina hubungan saling percaya dan meningkatkan interaksi dengan klien. Intervensi NIC memberikan pilihan intervensi keperawatan pada klien isolasi sosial yaitu bantuan perawatan diri (Bulechek, et al, 2013). Hal ini bertujuan meningkatkan kontak dengan klien yaitu dengan memenuhi kebutuhan harian klien seperti mandi, berhias, makan, dan eliminasi. Namun demikian diperlukan juga strategi lain yaitu dengan memperhatikan jarak ketika interaksi dengan klien pada area yang ditoleransi oleh klien agar mengurangi kecemasan klien. Mencari tempat berinteraksi yang sepi dan kondusif dan berada di luar dari wilayah teritori 
klien agar klien merasa tidak terancam teritorinya. Strategi posisi tubuh juga penting dimana ketika klien merasa terancam dengan bertatap muka maka posisi diubah menjadi posisi duduk menyamping dan perawat dapat memberikan sentuhan pada saat yang tepat dan dilakukan dengan hati-hati (Stuart, Keliat \& Pasaribu, 2016).

Tanda dan gejala isolasi sosial dapat berkurang dengan diberikan tindakan keperawatan sesuai rencana asuhan keperawatan yang telah ditetapkan. Penelitian menunjukkan bahwa tanda dan gejala isolasi sosial dapat berkurang setelah klien mendapat asuhan keperawatan isolasi sosial secara berkesinambungan (Komala, Mustikasari \& Wardani, 2017). Penelitian lain juga menemukan bahwa terjadi penurunan tanda dan gejala isolasi sosial yang ada pada klien pada aspek kognitif, afektif, fisiologis, perilaku dan sosial (Rachmawati, Keliat \& Wardani 2015). Respons kognitif terjadi penurunan yaitu klien mulai merasa aman dekat dengan orang lain dan mulai mempunyai ketertarikan pada kegiatan sosial yang ada di ruangan (Rachmawati, et al, 2015; Renidayati, et al, 2008).

Respons afektif terjadi penurunan ditunjukkan dengan klien mulai merasa aman dan nyaman dengan perawat dan tidak takut berada didekat perawat (Rachmawati, et al, 2015; Wakhid, et al, 2013; Townsend, 2014). Perubahan pada aspek fisiologis yaitu dari hari pertama perawatan klien sulit tidur namun pada hari ke enam klien mulai mudah tidur (Rachmawati, et al, 2015; Wakhid, et al, 2013; Stuart, et al, 2016). Respons sosial klien setelah diberikan intervensi yaitu klien menjadi mau berinteraksi dan berkomunikasi dengan perawat dan mampu berpartisipasi dalam kegiatan sosial di ruangan seperti jalan santai dan senam pagi (Rachmawati, et al, 2015; Keliat, et al, 1999). Respons perilaku klien Tn. P secara umum belum terjadi penurunan tanda dan gejala isolasi sosial yaitu klien masih berdiam diri di kamar, tidak ada kontak mata dan sering melamun sendirian.

Hambatan dalam proses pemberian asuhan keperawatan kepada klien yaitu lama perawatan, terapi psikofarmaka dan kesinambungan proses perawatan. Brady (2004) dalam Syafrini, Keliat dan Putri (2015) menyebutkan bahwa jarak antara munculnya gejala dengan perawatan dan pengobatan pertama akan mempengaruhi kecepatan dan kualitas respons pengobatan dan gejala negatif yang muncul, dimana semakin cepat klien mendapat pengobatan setelah terdiagnosis maka akan semakin cepat dan bermakna perubahan pada respons yang ditampilkan klien.

Hambatan yang lain yaitu klien mendapat terapi pengobatan yang dapat mempengaruhi tanda dan gejala isolasi sosial klien. Penelitian menunjukkan bahwa pemberian terapi psikofarmaka dapat menyebabkan tidak adanya hubungan yang signifikan antara pemberian asuhan keperawatan dengan pendekatan manajemen, kompensasi dan penghargaan serta hubungan profesional dengan tanda dan gejala klien isolasi sosial (Syafrini, Keliat \& Putri, 2015). Proses asuhan keperawatan pada klien berakhir karena masa rawat inap klien sudah mencapai batas maksimal hari rawat menurut kebijakan rumah sakit dan jaminan kesehatan. Klien pulang dijemput keluarga yang bekerjasama dengan pemerintah kabupaten Tasikmalaya. Walaupun kondisi klien belum maksimal, proses pemulangan tetap harus dilakukan. Pemberian asuhan keperawatan diakhiri di rumah sakit dan akan dilanjutkan di rumah. Oleh karena itu perlunya pendidikan kesehatan bagi keluarga agar keluarga mampu merawat klien ketika di rumah berupa psikoedukasi keluarga (Rachmawati, et al, 2015).

Beberapa studi telah dilakukan sebagai alternatif untuk mengatasi masalah isolasi sosial dengan memberikan berbagai intervensi keperawatan yaitu Social Affiliation Enhancement Tasks,SocializationEnhancement, Social Network Intervention, Behavior Modification:social skills, e-Intervention, Strategies Against Stigma and Discrimination (SASD), Psycho-education Social Skills Training (SST), dan Cognitive Behavioral Therapy (CBT) (Kopelowicz \& Liberman, 2003; Li, et al, 2010; Gomes \& Miguel, 2012; Tarzian, et al, 2013; Bulechek, et al, 2013; McCarthy, et al, 2017; Chipps, Jarvis \& Ramlall, 2017).

\section{Simpulan}

Masalah keperawatan utama yang ditemukan pada klien kelolaan Tn. $\mathrm{P}$ yaitu masalah isolasi sosial. Proses pemberian asuhan keperawatan pada masalah isolasi sosial berfokus pada kemampuan klien membina hubungan saling percaya dan meningkatkan kemampuan klien berinteraksi secara bertahap. Faktor yang memengaruhi klien sulit mendapatkan hubungan saling percaya antara perawat dan klien yaitu faktor internal berupa klien memiliki penilaian negatif terhadap diri sendiri, orang lain serta lingkungan. Factor selanjutnya adalah faktor eksternal, klien menganggap perawat 
Faletehan Health Journal, 5 (2) (2018) 90-98

https://journal.Ippm-stikesfa.ac.id

ISSN 2088-673X | 2597-8667

sebagai stressor eksternal yang mengancam rasa aman dan nyamannya.

Intervensi keperawatanmemberikan manfaat bagi klien, hal ini ditandai dengan adanya penurunan tanda dan gejala isolasi sosial pada klien. Pemberian asuhan keperawatan memerlukan waktu untuk memberikan perubahan pada klien, namun karena keterbatasan waktu dalam masa perawatan maka diperlukan langkah lain berupa edukasi kepada keluarga agar keluarga mampu meneruskan perawatan pada klien selama di rumah. Rencana tindak lanjut terhadap kondisi klien yang belum maksimal dapat dilakukan dengan memberikan intervensi-intervensi terbaru yang mempunyai evidence based practice dan melakukan rujukan kepada perawat spesialis jiwa yang memiliki kompetensi yang lebih mumpuni.

\section{Referensi}

Bulechek, G. M. , Butcher, H. K. , Dochterman, J. M. , \& Wagner, C. M. (Eds) (2013). Nursing intervention classification (NIC). 6th Ed. St, Louis Missouri: Mosby Elsevier.

Cacioppo, J. T. , Cacioppo, S. , Capitanio, J. P. \& Cole, S. W. (2015). The neuroendocrinology of social isolation. The Annual Review of Psychology, 66(9), 1-9.

Chipps, J. , Jarvis. , M. A. , \& Ramlall, S. (2017). The effectiveness of e-Interventions on reducing social isolation in older persons: A systematic review of systematic reviews. Journal of Telemedicine and Telecare. sagepub. co. uk/journalsPermissions. nav. DOI:10. 1177/1357633X17733773

DeVylder, J. E. , \& Hilimire, M. R. (2015). Suicide Risk, Stress Sensitivity, and Self-Esteem among Young Adults Reporting Auditory Hallucinations. Health and SocialWork, 40(3), 175-182. http://doi. org

Gomes, L. M. \& Miguel, L. (2012). Nursing presence as a nursing care: study of development of nursing presence in psychiatric context. Thesis. Research Gate: tersedia dalam https://www. researchgate. net

Halter, M. J. (2014). Varcarolis' foundation of psychiatric mental health nursing (7th ed. ). St. Louis: Saunders Elsevier

Harwood, L. , et al. (2007). Nurses' perceptions of the impact of a renal nursing professional practice model on nursing outcomes, characteristics of a practice environments and empowerment-part I. CANNT Journal, 17(1): 22

Herdman, T . H. , \& Kamitsuru, S. (2015). Diagnosis KeperawatanDefinisi \& Klasifikasi2015-2017 Edisi 10. Jakarta: EGC.

Jumaini, Keliat, B. A. \& Hastono, S. P. (2010). Pengaruh cognitive behavioral social skills training (CBSST) terhadap kemampuan bersosialisasi klien isolasi sosial di BLU RS DR. H. Marzoeki Mahdi. Tesis. Depok: UI ANA.

Junardi, Daulima, N. H. C. \& Wardani, I. Y. (2015). Asuhan keperawatan spesialis j iwa pada klien dengan isolasi sosial melalui pendekatan teori stres adaptasi Stuart di ruang Antareja Rumah Sakit dr. H. Marzoeki Mahdi Bogor. Karya Ilmiah Akhir. Depok: UI ANA.

Keliat, B. A. , \& Akemat. (2010). Model praktik keperawatan profesional jiwa. Jakarta: Penerbit Buku Kedokteran EGC.

Keliat, B. A, Akemat, Helena, N. , dan Nurhaeni, H. (2011). Keperawatan Kesehatan Jiwa Komunitas CMHN (Basic Course). Jakarta: EGC.

Keliat, B. A. , \& Pawirowiyono. (2015). Keperawatan jiwa: terapi aktivitas kelompok(2nd ed. ). Jakarta: Penerbit Buku Kedokteran EGC.

Keliat, B. A. , Panjaitan, R. U. , Mustikasari, \& Helena, N. (1999). Pengaruh model terapi aktivitas kelompok sosialisasi (TAKS) terhadap kemempuan komunikasi verbal dan non verbal pada klien menarik diri di rumah sakit jiwa. Jurnal Keperawatan Indonesia. 2 (8).

Kemenkes RI. (2013). Riset kesehatan dasar (RISKESDAS) 2013. Laporan Nasional 2013. Jakarta: Badan Penelitian dan Pengembangan Kesehatan Kementrtian Kesehatan RI. http://doi. org

Komala, E. P. E. , Mustikasari \& Wardani, I. Y. (2017). Perubahan tanda gejala dan kemampuan klien isolasi social setelah dinerikan latihan keterampilan social dan psiedukasi keluarga. Karya Ilmiah Akhir. Depok: UIANA.

Kopelowicz, A. \& Liberman, R. (2003). Integrating treatment with rehabilitation for persons with major mental illnesses. Psychiatric Services, 54 (11): 25-32.

Li, J. , Huang, Y. G. , Ran, M. S. , Fan, Y. , Chen, W. , Lacko, S. E. , \& Thornicroft, G. (2010). 
Community-based comprehensive intervention for people with schizophrenia in Guangzhou, China: effects on clinical symptoms, social functioning, internalized stigma and discrimination. Asian Journal of Psychiatry. https://doi. org/10. 1016

Massom, M. R. (2016). Social isolation of the stateless and the destitute: A study on the Refuge-Camp and the Sullied Slum of Dhaka City.

McCarthy, J. M., Bradshaw, K. R. , Catalano, L. T., Garcia, C. P., Malik, A., Bennett, M. E. \& Blanchard, J. J. (2017). Negative symptoms and the formation of social affiliative bonds in schizophrenia. Schizophrenia research. http://dx. doi. org

Napolion, K. , Keliat, B. A. , \& Mustikasari. (2012). Penerapan terapi spesialis keperawatan jiwa social skills training dan cognitive behavior therapy pada klien isolasi sosial dengan pendekatan model hubungan interpersonal H. E. Peplau di RS Marzoeki Mahdi Bogor. Karya Ilmiah Akhir Spesialis. Depok: UI ANA.

Penaloza, M. R., Fuentealba, P. G. \& Gallardo, P. C. (2017). Sex differences and the influence of social factors in a Chilean urban psychiatric hospital population. International Journal of Social Psychiatry, 17. 1-14.

Rachmawati, U., Keliat, B. A. , \& Wardani, I. Y. (2015). Tindakan keperawatan pada klien, keluarga dan kader kesehatan jiwa dengan diagnosa keperawatan isolasi sosial di komunitas. Jurnal Keperawatan Jiwa. 3 (2): 97-106.

Renidayati. ,Keliat,B. A. , \& Sabri, L (2008) Pengaruh social skills training pada klien isolasi sosial di Rumah Sakit Jiwa Prof HB Saanin Padang Sumatera Barat. Tesis. Depok: UIANA.

Siegrist, K. , Millier, A. , Amri, I. , Aballea, S. , \& Toumi, M. (2015). Association between social contact frequency and negative symptoms, psychosocial funtioning and quality of life in patient with schizophrenia. Psychiatry Research. 230(15): 860866

Stuart, G. W, Keliat,B. A. , Pasaribu,J. (2016) Prinsip dan praktik keperawatan kesehatan jiwa Stuart, Edisi Indonesia. Jakarta: Elsevier

Syafrini, R. O. , Keliat, B. A. , \& Putri, Y. S. E. (2015). Efektifitas implementasi asuhan keperawatan isolasi sosial dalam MPKP jiwa terhadap kemampuan klien. JurnalNers. 10(1): 175-182

Tarzian, E. , Tognoni, G. , Bracco, R. , Ruggieri, E. D. , Ficociello, R. A. , Mezzina, R. , \& Pillo, G. (2013). Social Network Intervention in patients with schizophrenia and marked social withdrawal: A randomized controlled study. Psychiatry. 58(11): 622-631

Townsend, M. C. (2014). Psychiatric nursing: Assessment, care plans, and medications (9th ed. ). Philadelphia: F. A. Davis Company.

Townsend, M. C. (2011). Nursing diagnoses in psychiatric nursing: Care plans and psychotropic medications. 8th Ed. Philadelphia: F. A. Davis Company.

Trimelia. (2011). Asuhan keperawatan klien halusinasi. Jakarta: CV Trans Info Media.

Wakhid, A. , Hamid, A. Y. S. , \& Helena, N. (2013). Penerapan terapi latihan keterampilan sosial pada klien isolasi sosial dan harga diri rendah dengan pendekatan model hubungan interpersonal Peplau di RS Dr Marzoeki Mahdi Bogor. Jurnal Keperawatan Jiwa. (1) $1: 34-48$.

WHO. (2011). Improving health system and services for mental health (Mental health policy and service guidance package). Geneva: WHO Press.

Yosep, I. , \& Sutini, T. (2014). Buku ajar keperawatan jiwa. Bandung: PT Refika Aditama. 